\title{
REVIEW
}

\section{Mucoactive drugs}

\author{
R. Balsamo*, L. Lanata* and C.G. Egan"
}

\begin{abstract}
Mucus hypersecretion is a clinical feature of severe respiratory diseases such as asthma, cystic fibrosis and chronic obstructive pulmonary disease. Airway mucosal infection and/ or inflammation associated with these diseases often gives rise to inflammatory products, including neutrophil-derived DNA and filamentous actin, in addition to bacteria, apoptotic cells and cellular debris, that may collectively increase mucus production and viscosity. Mucoactive agents have been the medication of choice for the treatment of respiratory diseases in which mucus hypersecretion is a clinical complication. The main purpose of mucoactive drugs is to increase the ability to expectorate sputum and/or decrease mucus hypersecretion. Many mucoactive drugs are currently available and can be classified according to their putative mechanism of action. Mucoactive medications include expectorants, mucoregulators, mucolytics and mucokinetics. By developing our understanding of the specific effects of mucoactive agents, we may result in improved therapeutic use of these drugs. The present review provides a summary of the most clinically relevant mucoactive drugs in addition to their potential mechanism of action.
\end{abstract}

KEYWORDS: N-Acetylcysteine, carbocysteine, erdosteine, mucoactive, mucus

. $\mathrm{n}$ healthy individuals, mucus secretion is not excessive and mucus continuously removed by epithelial ciliated cells, then propelled towards the larynx for swallowing [1]. However, an increase in airway mucus secretion can be problematic, especially if the rate of secretion exceeds the rate at which it can be removed by normal ciliary action. Increased mucus secretion (hypersecretion) is a clinical feature of severe respiratory diseases, such as asthma, cystic fibrosis (CF) and chronic obstructive pulmonary disease (COPD). Typically during infection and/or inflammation, the airway mucosa responds by increasing the volume of mucus that is secreted. This response is mainly due to hyperplasia and hypertrophy of goblet cells and the submucosal gland, a phenomenon recognised as secretory hyperresponsiveness [2]. The inflammatory process results in loss of cells and ciliary function, destruction of the surfactant layer by airway phospholipases and alteration of the biophysical properties of the mucus [3, 4]. In addition, by-products accumulated during the inflammatory process include neutrophil-derived DNA and filamentous actin (F-actin), dead/apoptotic cells, bacteria and cell debris. Collectively, these factors contribute to mucus purulence, and when expectorated, this mucus is termed sputum [5].

Mucus is a highly oligomerised mucin polymer composed of water and various macromolecular glycoproteins as part of its gel structure [6, 7]. Drugs that affect airway secretion have been produced for many years now, their main use being to cleanse the respiratory tract. Drugs that are designed to specifically alter the viscoelastic properties of mucus in addition to promoting secretion clearance are characterised as "mucoactive". Previous attempts have been made to characterise agents that affect mucus, although they sometimes lacked simplicity $[8,9]$. The main difficulty involved with characterising mucoactive agents is due to the fact that many drugs exhibit overlapping effects. Regardless, mucoactive drugs can be broadly and simply characterised into several major groups according to their main actions [2]. Mucoactive drugs can be classified as expectorants, mucoregulators, mucolytics or mucokinetics, based on their potential mechanism of action (table 1 and fig. 1).

\section{EXPECTORANTS}

An expectorant can be defined as an agent that induces discharge or expulsion of mucus from the respiratory tract. This typically requires a coughing or sneezing action to loosen and bring up the mucus from the lungs or upper respiratory tract. These events can be seen as beneficial if mucus plugs that obstruct large, medium or small airways are dislodged. Effects following
AFFILIATIONS

*Dompé SPA, Milan, and "Primula Multimedia SRL, Ospedaletto, Pisa, Italy.

CORRESPONDENCE

L. Lanata Dompé SPA Via San Martino 12-12a 20122 Milan Italy E-mail: luigi.lanata@dompe.it

Received:

March 242010

Accepted after revision: April 122010

PROVENANCE

Publication of this peer-reviewed article was supported by Dompé SPA, Italy (unrestricted grant, European Respiratory Review issue 116) 
expectorant medication can improve alveolar aeration and provide relief from neural irritation triggered by mechanical properties of the mucus plugs or effects of their inflammatory components. Together, these may in turn reduce the mechanical effort of breathing and dyspnoea. The precise mechanism by which expectorants exert their action is still unclear, although it is thought that they may act as irritants to gastric vagal receptors, and recruit efferent parasympathetic reflexes that induce glandular exocytosis of a less viscous mucus mixture $[9,10]$. Some frequently used expectorants include aerosol (hypertonic saline), iodide-containing compounds, glyceryl guaiacolate (guaifenesin) and ion channel modifiers, such as the P2Y2 purinergic agonists. These agents are addressed in detail below.

\section{Hypertonic saline}

Aerosol using hypertonic solution (saline, urea or ascorbic acid) has been previously thought to induce ciliary motility, proteolysis and mucus liquefaction [8]. This was attributed to intra- and intermolecular binding and osmotic hydration of luminal fluid. Studies have shown that long-term use of inhaled hypertonic saline improves pulmonary function in patients with $\mathrm{CF}$, and inhaled mannitol has also been shown to be beneficial in non-CF bronchiectasis [11-13]. However, a meta-analysis of short-term clinical studies suggested that nebulised hypertonic saline improved mucociliary clearance in CF only, but was less effective than DNase [14]. Regardless, this method (either with saline or mannitol) has been proven to be an extremely useful tool for the generation of sputum for diagnostic and research purposes [11-13].

\section{lodide-containing compounds}

Iodide-containing agents are considered to be expectorants that are thought to promote the secretion of airway fluid. Although iodides have long been used as expectorants, their clinical use has been debated, due to their potential toxicity [8, $10,15]$. Iodinated glycerol, first introduced in 1915, reduces chest discomfort and offers anti-tussive effects in patients with chronic bronchitis, without affecting dyspnoea or lung function [16]. Domiodol, another iodinated organic compound, has been shown to significantly increase secretion volume in adult subjects with chronic bronchitis $[8,17]$. Furthermore, domiodol has been shown to significantly reduce symptoms of acute infectious pulmonary diseases or acute flare-ups of chronic bronchitis effects in children [18].

\section{Guaifenesin (glyceryl guaiacolate)}

Guaifenesin has no mucolytic action but may reduce bronchial sputum surface tension. No evidence is available to suggest antiseptic or anti-tussive effects. The main benefit offered by guaifenesin appears to be as an expectorant for the symptomatic treatment of coughs, producing small quantities of thick viscous secretions. Guaifenesin can stimulate the cholinergic pathway and increase mucus secretion from the airway submucosal glands. However, guaifenesin has not been shown to be clinically effective in randomised controlled trials $[19,20]$.

\section{Ion channel modifiers}

Tricyclic nucleotides (uridine triphosphate and adenosine triphosphate) regulate ion transport through P2Y2 purinergic receptors that increase intracellular calcium. Nebulised uridine

\section{TABLE 1 Mucoactive drugs and their potential mechanisms of action}

Mucoactive drugs

Potential mechanism of action

\section{Expectorants}

Hypertonic saline

Guaifenesin

Mucoregulators

Carbocysteine

Anticholinergic agents

Glucocorticoids

Macrolide antibiotics

\section{Mucolytics}

N-Acetylcysteine

N-Acystelyn

Erdosteine

Dornase alfa

Gelsolin

Thymosin $\beta_{4}$

Dextran

Heparin

Mucokinetics ${ }^{\#}$

Bronchodilators

Surfactants

Ambroxol

Decreases secretion volume

Severs actin filament cross-links

Severs actin filament cross-links
Increases secretion volume and/or hydration

Stimulates secretion and reduces mucus viscosity

Metabolism of mucus producing cells, antioxidant and anti-inflammatory effects, modulates mucus production

Reduces airway inflammation and mucin secretion

Reduces airway inflammation and mucin secretion

Breaks disulphide bonds linking mucin polymers

Antioxidant and anti-inflammatory effects

Increases chloride secretion and breaks disulphide bonds

Modulates mucus production and increases mucociliary transport

Hydrolyses the DNA in mucus and reduces viscosity in the lungs

Breaks hydrogen bonds and increases secretion hydration

Breaks both hydrogen and ionic bonds

Improves cough clearance by increasing expiratory flow

Decreases sputum/mucus adhesiveness

Stimulates surfactant production and inhibits neuronal sodium channels

\#: also referred to as cough clearance promoters 

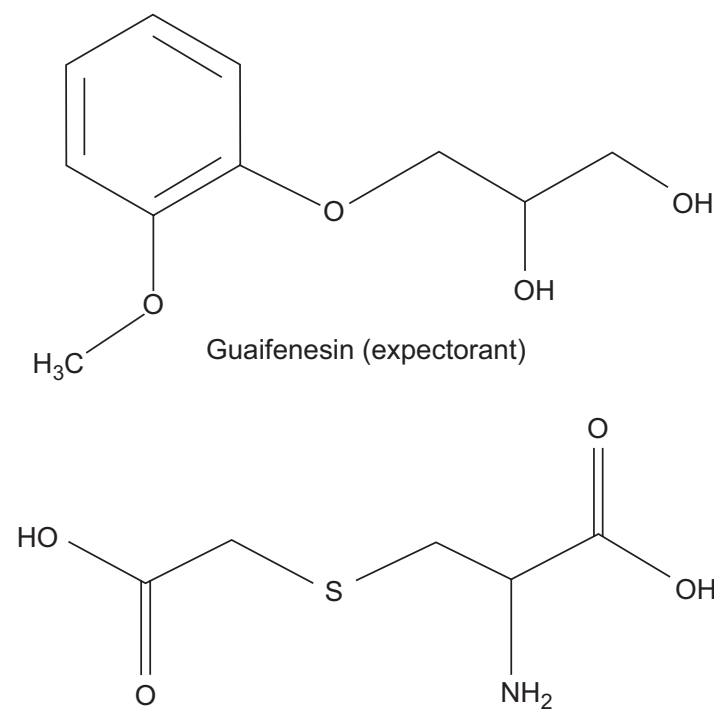

Carbocysteine (mucoregulator)<smiles>CC(CS)C(=O)O</smiles><smiles>CC(N)=O</smiles>

$N$-Acetylcysteine (mucolytic)

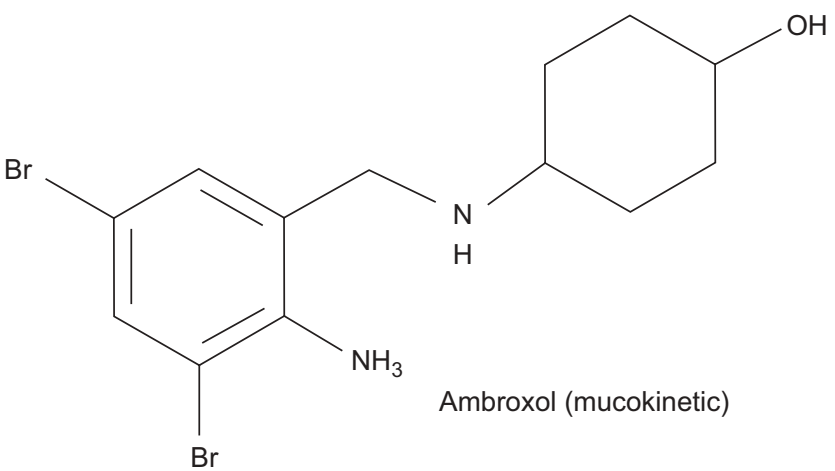

FIGURE 1. Chemical structures of selected expectorant, mucoregulatory, mucolytic and mucokinetic drugs

triphosphate aerosol in the presence or absence of amiloride has been shown to provide enhanced mucociliary clearance in healthy subjects [21]. P2Y2 purinergic receptor agonists have been recently developed and phase 3 studies are currently in progress [22].

\section{MUCOREGULATORS}

Drugs that regulate mucus secretion or interfere with the DNA/F-actin network can be described as mucregulatory agents. Among others, they include carbocysteine, anticholinergics, glucocorticoids and macrolide antibiotics. The mechanism of action of these compounds is wide ranging. For example, carbocysteine, an antioxidant, has the ability to restore viscoelastic properties of mucus and provide anti-inflammatory effects, in addition to providing protective effects on respiratory cells. In contrast, Anticholinergic agents block parasympathetic nerve activity, thereby reducing mucus secretion. Instead, glucocorticoids are potent anti-inflammatory drugs that are purported to improve mucociliary clearance. These mucoregulatory agents are examined in greater detail below.

\section{Carbocysteine}

S-Carboxymethylcysteine (carbocysteine or SCMC; also available in the lysinate form, SCMC-Lys) is a mucoactive drug (fig. 1), has antioxidant and anti-inflammatory properties, and is commonly used for the treatment of COPD [23]. Pre-clinical and clinical studies on the pharmacological properties of SCMC have demonstrated that this cysteine derivative has the ability to increase the synthesis of sialomucins, important structural components of mucus. In effect, SCMC resets the balance between sialomucins and fucomucins, possibly by intracellular stimulation of sialyl transferase activity [24], restoring the viscoelastic properties of mucus [25]. SCMC is not thought to act directly upon the mucus structure, in contrast to true mucolytic agents, such as $N$-acetylcysteine (NAC) or $N$-acystelyn (NAL). Evidence from animal studies suggests that SCMC increases chloride transport across the airway epithelium, which may contribute towards its mucoregulatory action [26]. In addition to the mucoregulatory action exerted by carbocysteine, the mechanism of action by which it provides anti-inflammatory effects has also been investigated. In pre-clinical and clinical studies, carbocysteine has been shown to reduce neutrophil infiltration into the airway lumen [27], decrease levels of interleukin (IL)-8, IL-6 cytokine levels and 8 -isoprostane exhaled in chronic obstructive pulmonary disease [28]. Since the chemotactic recruitment of peripheral blood mononuclear cells into the lung by IL-8 plays a crucial role in the development and maintenance of several inflammatory diseases, the inhibition of IL-8 production may contribute towards the therapeutic effect of SCMC-Lys. These anti-inflammatory effects have previously been directly attributed to scavenging effects of the thioether drug group on reactive oxygen species (ROS) [29, 30]. Carbocysteine may also modulate airway inflammation by reducing the production of cytokines in rhinovirus infections [31]. It has also been shown that carbocysteine inhibits the adherence of bacteria and viruses to ciliated epithelial cells in vitro [31, 32].

Additional evidence has shown that respiratory cells treated with SCMC-Lys stimulate a CF transmembrane conductance regulator (CFTR)-like channel that results in a significant increase in chloride and glutathione (GSH) membrane flux [33]. Furthermore, it has also been recently demonstrated that SCMC-Lys provides protective effects on human respiratory cells during oxidative stress [34]. In this particular study, cells exposed to oxidative stress and then treated with SCMC-Lys were shown to stimulate both GSH and chloride membrane flux, increase GSH concentration and buffer the increase in ROS in cells expressing the CFTR channel [34]. These findings provide further mechanistic insights on how SCMC-Lys may exert its antioxidative protective effects.

In addition to demonstrating beneficial effects in vitro, SCMC is also recognised to provide benefit to patients. SCMC has been 
shown to be an effective and safe drug for the treatment of COPD in randomised clinical trials, reducing the incidence of exacerbations and improving patient quality of life [35-38]. However, it should be noted for the PEACE (Preventive Effect on ACute Exacerbation) study that subjects were Chinese (25\% nonsmokers) who had limited access to other drugs that target exacerbations (e.g. long-acting bronchodilators and inhaled corticosteroids) [35]. No significant toxicity has been reported either in animal models or following prolonged use in humans, and no drug interactions have been identified. Moreover, SCMC has been shown to improve oxidative stress and chronic inflammation associated with severe chronic diseases, in particular advanced cancer and cancer-related syndromes, both alone and in combination with other antioxidant drugs $[30,39,40]$.

\section{Anticholinergic agents}

Anticholinergic drugs are frequently used as mucoregulators. Cholinergic parasympathetic nerve activity is an active stimulus for mucus secretion in human airways. This secretary response is mediated via M3 muscarinic receptor, expressed on submucosal airway cells. Anticholinergic medication, including atropine, ipratropium, scopolamine, glycopyrrolate and tiotropium, block these secretory reflexes, and reduce glandular output and sputum volume [41-43]. Atropine (often administered as atropine methonitrate) has been shown to block mucociliary clearance of the gel, but not the mucus sol phase. In contrast, ipratropium bromide does not appear to affect mucociliary transport [8]. The M1 receptor is not involved with mucus secretion but, in combination with M3, may control water secretion [44, 45].

\section{Glucocorticoids}

Glucocorticoids are potent anti-inflammatory agents and widely used in the management of acute exacerbations in patients with asthma or COPD. Glucocorticoids are purported to influence mucociliary clearance. Prednisolone is a glucocorticoid that has been shown to provide improvement in lung clearance in stable asthmatics [46]. However, it is generally accepted that steroids only have limited effects on mucus hypersecretion.

\section{Macrolide antiobiotics}

Macrolide antibiotics have been successfully used to treat a range of chronic, inflammatory lung disorders [47]. Macrolide antibiotics include erythromycin, azithromycin, clarithromycin, roxithromycin. Macrolide therapy using either azithromycin or clarithromycin is now considered standard care therapy for CF. Clinically, macrolides have been shown to reduce sputum production in severe bronchorrhea, diffuse panbronchitis, sinobronchial syndrome and otitis [48]. The precise mechanism(s) of action of macrolide antibiotics still requires further investigation, although their specific effects include inhibition of neutrophil chemotaxis, lymphocyte and macrophage function and modulation of airway smooth muscle and neural tone [48]. Data in COPD patients are limited and sometimes contradictory but generally suggest a potential clinical benefit $[46,49]$. However, the long-term safety of these antibiotics for the treatment of COPD still needs to be addressed [50].

\section{MUCOLYTICS}

Mucolytic can be defined as drugs that decrease mucus viscosity and can be categorised into either "classic" if they depolymerise mucin glycoproteins or "peptide" mucolytics that depolymerise DNA and F-actin polymer networks.

\section{Classic mucolytics}

NAC is a mucolytic drug (fig. 1), in addition to possessing antioxidant and anti-inflammatory properties, that is commonly used for the treatment of COPD [23]. Aerosol administration of NAC may dissociate mucin disulphide bonds and other disulphide bond cross-linked gel components to reduce viscosity. A number of observations on NAC suggest that it not only exerts mucolytic properties, but also antioxidant effects, which may protect against free radical damage [8, 51-54]. NAC has also been shown to decrease airway inflammation by reducing lysozyme and lactoferrin concentrations in smokers [55], inhibiting neutrophil and monocyte chemotaxis and oxidative burst responses in vitro [56], reducing the activation and number of neutrophils and macrophages in bronchoalveolar lavage fluid in smokers $[57,58]$, and inhibiting the adherence of bacteria to ciliated epithelial cells in vitro [59]. Some evidence suggests that oral NAC may reduce exacerbation rates in chronic bronchitis [60, 61]. However, a more recent controlled randomised clinical trial did not demonstrate a reduction in the frequency of exacerbations with NAC in patients with COPD, but only in the subgroup not taking inhaled corticosteroids [62]. Furthermore, NAC treatment of patients with stable, moderate-tosevere COPD has been shown to benefit physical performance, which may be attributed to air trapping [63]. However, like carbocysteine, little evidence is currently available in humans showing that NAC exerts its action by direct effects on mucus.

The lysine salt alternative to NAC is NAL, also a mucolytic and antioxidant thiol compound. The main advantage of NAL over NAC might be that it has a neutral $\mathrm{pH}$ in solution, whereas NAC is acidic, and therefore an irritant when inhaled. Like NAC, NAL also exerts anti-inflammatory effects both in vitro and in vivo [64], and although large randomised trials have yet to be undertaken, this mucolytic drug could be interesting for the treatment of COPD.

More recently, other mucolytics like erdosteine and fudosteine, known as novel thiols, have also been synthesised $[65,66]$, to overcome problems observed with thiols such as NAC and NAL. Erdosteine is as an antioxidant and has mucolytic properties, in addition to the ability to reduce bacterial adhesiveness. A small randomised control trial showed fewer exacerbations, reduced hospital time and improved quality of life in patients with COPD that were treated with erdosteine when compared with placebo [67]; however, future clinical trials will be needed to confirm these preliminary results. In addition, in COPD patients that smoke, erdosteine has also been observed to reduce levels of ROS and cytokines (IL-6 and -8) in peripheral blood and bronchial secretions, respectively [68]. Fudosteine is a cysteine-donating compound with greater bioavailability than NAC. It reduces hypersecretion by downregulation of mucin gene expression. 


\section{Peptide mucolytics}

Unlike classic mucolytics that break down mucin networks, peptide mucolytics are designed to break down the highly polymerised DNA and F-actin network that is characteristic of pus. The proteolytic enzyme dornase alfa cleaves DNA polymers and has been developed for the long-term treatment of mucus hypersecretion in CF [69]. Furthermore, children with CF show improved lung function and outcome following treatment with dornase alfa [70]. Both gelsolin and thymosin $\beta 4$, conversely, are recognised to specifically depolymerise Factin polymers in CF sputum, therefore reducing its' viscosity [71, 72]; however, these agents need to be further evaluated in clinical trials.

\section{Non-destructive mucolytics}

Unlike other mucolytics that cleave chemical bonds, nondestructive mucolytics dissociate or disrupt the polyionic oligosaccharide mucin network by a mechanism termed "charge shielding". Examples of these mucolytics include dextran and heparin, and although clinical studies are yet to be undertaken, in vitro and pre-clinical studies have demonstrated their efficacy [73-75].

\section{MUCOKINETICS}

The majority of mucokinetic agents (sometimes referred to as cough clearance promoters) increase mucociliary clearance by acting on the cilia. Although a wide range of mucokinetics that increase ciliary beat frequency are available, these agents have little effect on mucociliary clearance in patients with pulmonary disease [76]. Mucokinetic medications include broncodilators, tricyclic nucleotides and ambroxol (fig. 1). Surfactants also promote cough clearance of mucus by decreasing the surface adhesion between mucus and airway epithelium [77].

\section{Bronchodilators}

There is evidence in favour of the use of $\beta_{2}$-adrenergic agonists to enhance mucociliary clearance [78, 79]; however, other reports have observed little effect on mucociliary clearance [80]. Interestingly, recent reports have shown that salmeterol could restore secretory functions in CF airway submucosal gland serous cells [81], and that $\beta_{2}$-adrenergic agonists can enhance mucociliary clearance in patients with airway reversibility [82].

\section{Ambroxol}

Ambroxol is thought to stimulate surfactant and mucus secretion, yet promote normalisation of mucus viscosity in viscid secretions. The results of clinical studies of ambroxol are conflicting in that some found clinical benefit [83], whereas others did not [84]. However, a recent systematic review provides evidence of a generalised benefit using ambroxol for a range of parameters, including secretolytic activity (promoting mucus clearance), anti-inflammatory and antioxidant activity and exerts local anaesthetic effect [85].

\section{SUMMARY}

The present review provides a summary of the most clinically relevant mucoactive drugs used worldwide in the management of several acute and chronic respiratory diseases, with particular reference to their potential mechanisms of action. Although the precise mechanism of action of several mucoactive drugs is fairly well established, difficulty still exists regarding how they are sometimes classified, due to overlapping effects that they exhibit. Only by developing our understanding of the mechanism of action and specific effects exerted by mucoactive agents, we may in turn offer improved therapeutic use of these drugs.

\section{STATEMENT OF INTEREST}

R. Balsamo and L. Lanata are employees of Dompé SPA, Italy.

\section{REFERENCES}

1 Wanner A, Salathe M, O'Riordan TG. Mucociliary clearance in the airways. Am J Respir Crit Care Med 1996; 154: 1868-1902.

2 Rubin BK. The pharmacologic approach to airway clearance: mucoactive agents. Respir Care 2002; 47: 818-822.

3 King M, Rubin BK. Pharmacological approaches to discovery and development of new mucolytic agents. Adv Drug Deliv Rev 2002; 54: 1475-1490.

4 Rogers DF, Barnes PJ. Treatment of airway mucus hypersecretion. Ann Med 2006; 38: 116-125.

5 Rubin BK, van der Schans CP, eds. Therapy for Mucus Clearance Disorders. C. Lenfant, executive editor. Biology of the Lung Series. New York, Marcel Dekker, 2004

6 Lopez-Vidriero MT. Airway mucus; production and composition. Chest 1981; 80: 799-804.

7 Kaliner M, Marom Z, Patow C, et al. Human respiratory mucus. J Allergy Clin Immunol 1984; 73: 318-323.

8 Braga PC, Ziment I, Allegra L. Classification of agents that act on bronchial mucus. In: Braga PC, Allegra L, eds. Drugs in Bronchial Mucology. New York, Raven Press, 1989, pp. 59-67.

9 Yuta A, Baraniuk JN. Therapeutic approaches to airway hypersecretion. Curr Allergy Asthma Rep 2005; 5: 243-251.

10 Ziment I. Respiratory Pharmacology and Therapeutics. Philadelphia, WB Saunders, 1988.

11 Donaldson SH, Bennett WD, Zeman KL, et al. Mucus clearance and lung function in cystic fibrosis with hypertonic saline. $N$ Engl J Med 2006; 354: 241-250.

12 Elkins MR, Robinson M, Rose BR, et al. National Hypertonic Saline in Cystic Fibrosis (NHSCF) Study Group. A controlled trial of long-term inhaled hypertonic saline in patients with cystic fibrosis. N Engl J Med 2006; 354: 229-240.

13 Wills P, Greenstone M. Inhaled hyperosmolar agents for bronchiectasis. Cochrane Database Syst Rev 2002; 1: CD002996.

14 Jones AP, Wallis CE. Recombinant human deoxyribonuclease for cystic fibrosis. Cochrane Database Syst Rev 2003; 3: CD001127.

15 Hendeles L, Weinberger M. A time to abandon the use of iodides in the management of pulmonary diseases. J Allergy Clin Immunol 1980; 66: 177-178.

16 Petty TL. The national mucolytic study: results of a randomized, double blind, placebo controlled study of iodinated glycerol in chronic obstructive bronchitis. Chest 1990; 98: 1309-1310.

17 Finiguerra M, De Martini S, Negri L, et al. Clinical and functional effects of domiodol and sobrerol in hypersecretory bronchopneumonias. Minerva Med 1981 26, 72: 1353-1360.

18 Fiocchi A, Grasso U, Zuccotti G, et al. Domiodol treatment for bronchopulmonary diseases in the paediatric age group: a doubleblind controlled clinical trial versus placebo. J Int Med Res 1988; 16: 31-38.

19 Sisson JH, Yonkers AJ, Waldman RH. Effects of guaifenesin on nasal mucociliary clearance and ciliary beat frequency in healthy volunteers. Chest 1995; 107: 747-751.

20 Yeates DB, Cohen VR, Davis AL, et al. Effect of glyceryl guaiacolate on bronchial clearance in patients with chronic bronchitis. Am Rev Respir Dis 1977; 115: 182. 
21 Olivier KN, Bennett WD, Hohneker KW, et al. Acute safety and effects on mucociliary clearance of aerosolized uridine $5^{\prime}$-triphosphate +/- amiloride in normal human adults. Am J Respir Crit Care Med 1996; 154: 217-223.

22 Kellerman D, Rossi Mospan A, Engels J, et al. Denufosol: a review of studies with inhaled P2Y2 agonists that led to phase 3. Pulm Pharmacol Ther 2008; 21: 600-607.

23 Rogers DF. Mucoactive drugs for asthma and COPD: any place in therapy? Expert Opin Investig Drugs 2002; 11: 15-35.

24 Havez R, Degand P, Roussel P, et al. Biochemical mechanism of action of cysteine derivatives on bronchial mucus. Poumon Coeur 1970; 26: 81-90.

25 Puchelle E, Girard F, Polu JM, et al. Effect of the mucoregulator Scarboxy-methyl-cysteine in patients with chronic bronchitis. Eur J Clin Pharmacol 1978; 14: 177-184.

26 Colombo B, Turconi P, Daffonchio L, et al. Stimulation of $\mathrm{Cl}^{-}$ secretion by the mucoactive drug $S$-carboxy-methylcysteinelysine salt in the isolated rabbit trachea. Eur Respir J 1994; 7: 1622-1628.

27 Asti C, Melillo G, Caselli GF, et al. Effectiveness of carbocysteine lysine salt monohydrate on models of airway inflammation and hyperresponsiveness. Pharmacol Res 1995; 31: 387-392.

28 Carpagnano GE, Resta O, Foschino-Barbaro MP, et al. Exhaled interleukine-6 and 8-isoprostane in chronic obstructive pulmonary disease: effect of carbocysteine lysine salt monohydrate (SCMCLys). Eur J Pharmacol 2004; 505: 169-175.

29 Pinamonti S, Venturoli L, Leis M, et al. Antioxidant activity of carbocysteine lysine salt monohydrate. Panminerva Med 2001; 43: 215-220.

30 Brandolini L, Allegretti M, Berdini V, et al. Carbocysteine lysine salt monohydrate (SCMC-LYS) is a selective scavenger of reactive oxygen intermediates (ROIs). Eur Cytokine Netw 2003; 14: 20-26.

31 Yasuda H, Yamaya M, Sazaki T, et al. Carbocysteine inhibits rhinovirus infection in human tracheal epithelial cells. Eur Respir J 2006; 28: 51-58.

32 Suer E, Sayrac S, Sarinay E, et al. Variation in attachment of Streptococcus pneumoniae to human pharyngeal epithelial cells after treatment with S-carboxymethylcysteine. J Infect Chemother 2008; 14: 333-336.

33 Guizzardi F, Rodighiero S, Binelli A, et al. S-CMC-Lys-dependent stimulation of electrogenic glutathione secretion by human respiratory epithelium. J Mol Med 2006; 84: 97-107.

34 Garavaglia ML, Bononi E, Dossena S, et al. S-CMC-Lys protective effects on human respiratory cells during oxidative stress. Cell Physiol Biochem 2008; 22: 455-464.

35 Zheng JP, Kang J, Huang SG, et al. Effect of carbocisteine on acute exacerbation of chronic obstrucitve pulmonary disease (PEACE Study): a randomised placebo-controlled study. Lancet 2008; 371: 2013-2018.

36 Allegra L, Cordaro CI, Grassi C. Prevention of acute exacerbations of chronic obstructive bronchitis with carbocysteine lysine salt monohydrate: a multicenter, double-blind, placebo-controlled trial. Respiration 1996; 63: 174-180.

37 Yasuda H, Yamaya M, Sasaki T, et al. Carbocysteine reduces frequency of common colds and exacerbations in patients with chronic obstructive pulmonary disease. J Am Geriatr Soc 2006; 54: 378-380.

38 Macciò A, Madeddu C, Panzone F, et al. Carbocysteine: clinical experience and new perspectives in the treatment of chronic inflammatory diseases. Expert Opin Pharmacother 2009; 10: 693-703.

39 Pena LR, Hill DB, McClain CJ. Treatment with glutathione precursor decreases cytokine activity. JPEN J Parenter Enteral Nutr 1999; 23: 1-6.

40 Rahman I. Antioxidant therapeutic advances in COPD. Ther Adv Respir Dis 2008; 2: 351-74.

41 Meltzer EO. Intranasal anticholinergic therapy of rhinorrhea. J Allergy Clin Immunol 1992; 90: 1055-1064.
42 Gross NJ. Anticholinergic agents. In: Leff AR, ed. Pulmonary and Critical Care Pharmacology and Therapeutics. New York, McGraw-Hill, 1996; pp. 535-552.

43 Arai N, Kondo M, Izumo T, et al. Inhibition of neutrophil elastaseinduced goblet cell metaplasia by tiotropium in mice. Eur Respir J 2010; 35: 1164-1171.

44 Ramnarine SI, Haddad EB, Khawaja AM, et al. On muscarinic control of neurogenic mucus secretion in ferret trachea. J Physiol 1996; 494: 577-586.

45 Ishihara $\mathrm{H}$, Shimura $\mathrm{S}$, Satoh $\mathrm{M}$, et al. Muscarinic receptor subtypes in feline tracheal submucosal gland secretion. Am J Physiol 1992; 262: 223L-228L.

46 Agnew JE, Bateman JRM, Pavia D, et al. Peripheral airways mucus clearance in stable asthma is improved by oral corticosteroid therapy. Bull Eur Physiopath Respir 1984; 20: 295-301.

47 Martinez FJ, Curtis JL, Albert R. Role of macrolide therapy in chronic obstructive pulmonary disease. Int J Chron Obstruct Pulmon Dis 2008; 3: 331-350.

48 Gotfried MH. Macrolides for the treatment of chronic sinusitis, asthma, and COPD. Chest 2004; 125: 52S-60S.

49 Seemungal TA, Wilkinson TM, Hurst JR, et al. Long-term erythromycin therapy is associated with decreased chronic obstructive pulmonary disease exacerbations. Am J Respir Crit Care Med 2008; 178: 1139-1147.

50 Crosbie PA, Woodhead MA. Long-term macrolide therapy in chronic inflammatory airway diseases. Eur Respir J 2009; 33: 171-181.

51 Tirouvanziam R, Conrad CK, Bottiglieri T, et al. High-dose oral Nacetylcysteine, a glutathione prodrug, modulates inflammation in cystic fibrosis. Proc Natl Acad Sci USA 2006; 103: 4628-4633.

52 Dauletbaev N, Fischer P, Aulbach B, et al. A phase II study on safety and efficacy of high-dose $\mathrm{N}$-acetylcysteine in patients with cystic fibrosis. Eur J Med Res 2009; 14: 352-358.

53 Dekhuijzen PN. Antioxidant properties of $N$-acetylcysteine: their relevance in relation to chronic obstructive pulmonary disease. Eur Respir J 2004; 23: 629-636.

54 Reichenberger F, Tamm M. N-Acetylcystein in der Therapie der chronischen Bronchitis. [N-acetylcysteine in the therapy of chronic bronchitis]. Pneumologie 2002; 56: 793-797.

55 Linden M, Wieslander E, Eklund A, et al. Effects of oral $\mathrm{N}$ acetylcysteine on cell content and macrophage function in bronchoalveolar lavage from healthy smokers. Eur Respir J 1988; 1: 645-650.

56 Kharazmi A, Nielsen H, Bendtzen K. Recombinant interleukin $1 \alpha$ and $\beta$ prime human monocyte superoxide production but have no effect on chemotaxis and oxidative burst response of neutrophils. Immunobiology 1988; 177: 32-39.

57 Eklund A, Eriksson O, Hakansson L, et al. Oral $\mathrm{N}$-acetylcysteine reduces selected humoral markers of inflammatory cell activity in BAL fluid from healthy smokers: correlation to effects on cellular variables. Eur Respir J 1988; 1: 832-838.

58 Bergstrand H, Bjornson A, Eklund A, et al. Stimuli-induced superoxide radical generation in vitro by human alveolar macrophages from smokers: modulation by $\mathrm{N}$-acetylcysteine treatment in vivo. J Free Radic Biol Med 1986; 2: 119-127.

59 Niederman MS, Rafferty TD, Sasaki CT, et al. Comparison of bacterial adherence to ciliated and squamous epithelial cells obtained from the human respiratory tract. Am Rev Respir Dis 1983; 127: 85-90.

60 Boman G, Backer U, Larsson S, et al. Oral acetyl cystine reduces exacerbation rate in chronic bronchitis, report of a trial organized by the Swedish Society for Pulmonary Disease. Eur J Respir Dis 1983; 64: 405-415.

61 Multicenter study group. Long term oral acetyl cystine in chronic bronchitis, a double blind controlled study. Eur J Respir Dis 1980; 61: 93-108. 
62 Decramer M, Rutten-van Mölken M, Dekhuijzen PN, et al. Effects of $\mathrm{N}$-acetylcysteine on outcomes in chronic obstructive pulmonary disease (Bronchitis Randomized on NAC Cost-Utility Study, BRONCUS): a randomised placebo-controlled trial. Lancet 2005; 365: 1552-1560.

63 Stav D, Raz M. Effect of $N$-acetylcysteine on air trapping in COPD: a randomized placebo-controlled study. Chest 2009; 136: 381-386.

64 Antonicelli F, Brown D, Parmentier M, et al. Regulation of LPSmediated inflammation in vivo and in vitro by the thiol antioxidant N-acystelyn. Am J Physiol Lung Cell Mol Physiol 2004; 286: L1319L1327.

65 Moretti M, Marchioni CF. An overview of erdosteine antioxidant activity in experimental research. Pharmacol Res 2007; 55: 249-254.

66 Rhee CK, Kang CM, You MB, et al. Effect of fudosteine on mucin production. Eur Respir J 2008; 32: 1195-1202.

67 Moretti M, Bottrighi P, Dallari R, et al. The effect of long-term treatment with erdosteine on chronic obstructive pulmonary disease: the EQUALIFE Study. Drugs Exp Clin Res 2004; 30: 143-152.

68 Dal Negro RW, Visconti M, Micheletto C, et al. Changes in blood ROS, eNO, and some pro-inflammatory mediators in bronchial secretions following erdosteine or placebo: a controlled study in current smokers with mild COPD. Pulm Pharmacol Ther 2008; 21 : 304-308.

69 Shak S. Aerosolized recombinant human DNase I for the treatment of cystic fibrosis. Chest 1995; 107: 65S-70S.

70 McPhail GL, Acton JD, Fenchel MC, et al. Improvements in lung function outcomes in children with cystic fibrosis are associated with better nutrition, fewer chronic Pseudomonas aeruginosa infections, and dornase alfa use. J Pediatr 2008; 153: 752-757.

71 Vasconcellos CA, Allen PG, Wohl ME, et al. Reduction in viscosity of cystic fibrosis sputum in vitro by gelsolin. Science 1994; 263: 969-971.

72 Kater A, Henke MO, Rubin BK. The role of DNA and actin polymers on the polymer structure and rheology of cystic fibrosis sputum and depolymerization by gelsolin or thymosin $\beta 4$. Ann NY Acad Sci 2007; 1112: 140-153.
73 Broughton-Head VJ, Shur J, Carroll MP, et al. Unfractionated heparin reduces the elasticity of sputum from patients with cystic fibrosis. Am J Physiol Lung Cell Mol Physiol 2007; 293: L1240-L1249.

74 Faure M, Moënnoz D, Montigon F, et al. Mucin production and composition is altered in dextran sulfate sodium-induced colitis in rats. Dig Dis Sci 2003; 48: 1366-1373.

75 Feng W, Garrett H, Speert DP, et al. Improved clearability of cystic fibrosis sputum with dextran treatment in vitro. Am J Respir Crit Care Med 1998; 157: 710-714.

76 Isawa T, Teshima T, Hirano T, et al. Effect of oral salbutamol on mucociliary clearance mechanisms in the lungs. Tohoku J Exp Med 1986; 150: 51-61.

77 Anzueto A, Jubran A, Ohar JA, et al. Effects of aerosolized surfactant in patients with stable chronic bronchitis: a prospective randomized controlled trial. JAMA 1997; 278: 1426-1431.

78 Daviskas E, Anderson SD, Eberl S, et al. Effects of terbutaline in combination with mannitol on mucociliary clearance. Eur Respir J 2002; 20: 1423-1429.

79 Frohock JI, Wijkstrom-Frei C, Salathe M. Effects of albuterol enantiomers on ciliary beat frequency in ovine tracheal epithelial cells. J Appl Physiol 2002; 92: 2396-2402.

80 Mortensen J, Hansen A, Falk M, et al. Reduced effect of inhaled $\beta_{2}$ adrenergic agonists on lung mucociliary clearance in patients with cystic fibrosis. Chest 1993; 103: 805-811.

81 Delavoie F, Molinari M, Milliot M, et al. Salmeterol restores secretory functions in cystic fibrosis airway submucosal gland serous cells. Am J Respir Cell Mol Biol 2009; 40: 388-397.

82 Sears MR. Safety of long-acting $\beta$-agonists: are new data really required? Chest 2009; 136: 604-607.

83 Germouty J, Jirou-Najou JL. Clinical efficacy of ambroxol in the treatment of bronchial stasis: clinical trial in 120 patients at two different doses. Respiration 1987; 51: 37-41.

84 Guyatt GH, Townsend M, Kazim F, et al. A controlled trial of ambroxol in chronic bronchitis. Chest 1987; 92: 618-620.

85 Malerba M, Ragnoli B. Ambroxol in the 21st century: pharmacological and clinical update. Expert Opin Drug Metab Toxicol 2008; 4: 1119-1129. 